\title{
Ruthenium-Free Preparation of 1,5-Disubstituted Triazoles by Alkylative Debenzylation of 1,4-Disubstituted Triazoles
}

Philip C. Bulman Page, *a

G. Richard Stephenson, *a

James Harvey,

Alexandra M. Z. Slawin. ${ }^{b}$

a School of Chemistry, University of East Anglia, Norwich Research Park, Norwich, Norfolk NR4 7TJ, U.K.

${ }^{\mathrm{b}}$ Molecular Structure Laboratory, School of Chemistry, University of St Andrews, Purdie Building, St. Andrews, Fife KY16 9ST, Scotland
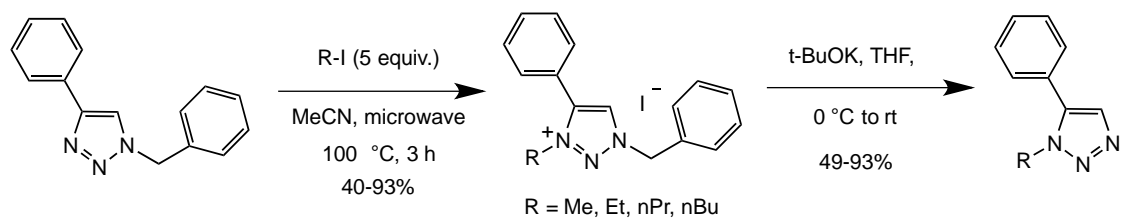

p.page@uea.ac.uk

Click here to insert a dedication.

\section{Received:
Accepted:
Published online:}

DOI:

Abstract: A method that cleanly converts the 1,4-disubstituted 1,2,3-triazole products of the copper-catalysed 'click' dipolar cycloaddition reaction of benzyl azide with terminal alkynes into 1,5-disubstituted triazoles is described. Selective $\mathrm{N}$-alkylation of 1,4-disubstituted 1,2,3-triazoles under microwave irradiation is followed by debenzylation of the resulting 1,3,4-trisubstituted triazolium cations by treatment with potassium tert-butoxide.

Key words 1,2,3-triazole, debenzylation, microwave, disubstituted, rearrangement

In recent years the Huisgen 1,3-dipolar cycloaddition reaction of organic azides to alkynes has gained a great deal of interest following the introduction of transition metal catalysis by Meldal in 2001. ${ }^{1}$ The Sharpless and Meldal laboratories independently reported that the use of a catalyst vastly improved both the regioselectivity and rate of the reaction, resulting in an extremely effective method for the synthesis of disubstituted 1,2,3-triazoles (e.g. Scheme 1).2,3
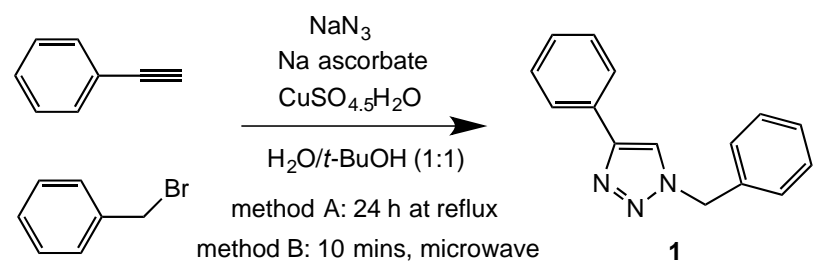

A: $86 \%, B: 91 \%$

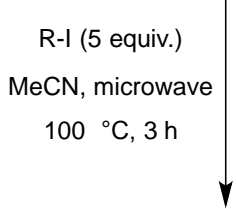
$2(\mathrm{R}=\mathrm{Me} ; 93 \%)$
$3(\mathrm{R}=\mathrm{Et} ; 86 \%)$
$4 \quad(\mathrm{R}=n-\mathrm{Pr} ; 44 \%)$
$5 \quad(\mathrm{R}=n-\mathrm{Bu} ; 40 \%)$

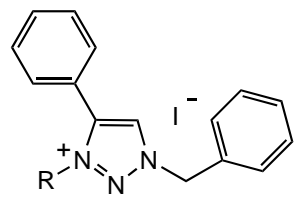

Scheme 1: Preparation of 1,3,4-trisubstituted 1,2,3-triazolium salts by a microwave-assisted selective $N$-akylation reaction.

Although relatively unreactive, substituted 1,2,3-triazoles, available through inexpensive copper-catalysed 'click' cycloaddition (CuAAC) reactions, are of value in a wide variety of research fields, including materials science ${ }^{4}$ and synthetic chemistry, ${ }^{5}$ as a ligating moiety in organometallic chemistry, ${ }^{6}$ for cyclopropanation chemistry, ${ }^{7}$ and as a pharmacophore in medicinal chemistry; ${ }^{8}$ they possess a range of biological activities, including antifungal, ${ }^{9}$ antibody, ${ }^{10}$ anti-cancer, ${ }^{11}$ anti- 
Alzheimer's, ${ }^{12}$ and anti-HIV activities. When converted into triazolium salts, they provide an important class of ionic liquids. ${ }^{13}$ 1,2,3-Triazoles have also been converted into a variety of other functionalities such as pyrroles, ${ }^{14}$ imidazoles and imidazolones. ${ }^{15}$

While the CuAAC 'click' reaction is general, rapid, and high yielding, it only takes place with terminal alkynes, and always introduces a 1,4-disubstituted 1,2,3-triazole; for the introduction of greater structural diversity, there would be substantial advantage if a wider range of substitution and functionality were accessible by modification of the triazole. While there have been many reported examples of the synthesis of 1,4-disubstituted 1,2,3-triazoles, there are far fewer of the 1,5-disubstituted regioisomer. The first selective synthesis of the 1,5-disubstituted triazole was reported by Fokin, ${ }^{16}$ which utilized ruthenium catalysts to yield the selected regioisomer in up to quantitative yield. While this method was effective, the high cost of the ruthenium catalyst makes this procedure less desirable. Other methods have been reported, but still have the disadvantage of requiring expensive transition metal catalysts or starting materials, or are carried out under unattractive conditions. ${ }^{17}$

We have been addressing this issue through a study of procedures for either the removal or the modification of 1,4substituted 1,2,3-triazoles. Our approach has involved initial $\mathrm{N}$ alkylation to form a more reactive triazolium salt. We describe herein an effective procedure for the $\mathrm{N}$-alkylation step mediated by microwave irradiation, and an investigation of reductive, nucleophilic and base-promoted transformations of the resulting 1,3,4-trisubstituted 1,2,3-triazolium cations. The single crystal X-ray structure of 1-benzyl-3-ethyl-4-phenyl-1,2,3triazolium iodide is also reported to confirm the regioselectivity of the $N$-alkylation reaction.

We chose the simple, readily available 1,2,3-triazole $\mathbf{1}$ as a test system (Scheme 1). ${ }^{18}$ A convenient in situ method for the CuAAC reaction was employed with phenylethyne, benzyl bromide and sodium azide using a sodium ascorbate / copper(II) sulfate protocol in $t$-butanol/water (1:1) under both standard thermal and microwave irradiation conditions. The product 1-benzyl-4phenyl-1,2,3-triazole 1 was obtained in $86 \%$ yield by heating at reflux for 24 hours. ${ }^{19}$ The microwave alternative proved far more convenient, requiring only 10 minutes at $125^{\circ} \mathrm{C}$, and gave a slightly improved yield (91\%) of the product, as described by Fokin. ${ }^{18}$ In practice. both were convenient routes to make the required starting material.

Triazolium salts were prepared through $N$-alkylation, first with methyl iodide in acetonitrile. Originally we used the methodology described by Hanelt, ${ }^{20}$ but due to low yields or long reaction times we again utilized microwave irradiation, which gave a much greater yield of salts with much lower reaction times. The most efficient reaction conditions (180 min at $100{ }^{\circ} \mathrm{C}$ ) gave the expected 1-benzyl-3-methyl-4-phenyl-1,2,3triazolium iodide $\mathbf{2}$ in $97 \%$ yield. ${ }^{21}$ The salt $\mathbf{2}$ has been prepared previously by Albrecht, and the 1,3,4-substitution pattern was proven by single crystal X-ray structure determination of a derived palladium complex. ${ }^{22}$ Using these irradiation conditions (Scheme 1), ethyl iodide proved similarly efficient, affording 1benzyl-3-ethyl-4-phenyl-1,2,3-triazolium iodide 3 in 86\% yield. The more hindered alkylating agents $n$-propyl iodide and $n$ - butyl iodide gave the corresponding triazolium salts $\mathbf{4}$ and $\mathbf{5}$ in rather lower yields ( $44 \%$ and $40 \%$, respectively), but in sufficient quantities for our intended study of the reactivity of the triazolium cations. The ethylated triazolium iodide $\mathbf{3}$ is highly crystalline, and recrystallization from dichloromethane/petroleum ether gave high quality crystals. Single crystal X-ray structural determination of $\mathbf{3}$ (Figure 1) confirmed that ethylation had taken place at N3.23 In this series of compounds, the expected selectivity for $\mathrm{N}$-alkylation at N3 is thus unambiguously known for structures $\mathbf{2}$ and $\mathbf{3}$ and can be reliably extrapolated for the whole series by comparison of NMR spectra: on the basis of consistent chemical shifts observed for the C5 methine hydrogen atom of the triazolium ring in all four alkylation products, ${ }^{24}$ the entire series is assigned as the 1benzyl-3-alkyl-4-phenyl-1,2,3-triazolium regioisomers. By varying temperature and reaction time, an efficient and general microwave-mediated regioselective $N$-methylation procedure was developed, involving four to five equivalents of methyl iodide, acetonitrile as solvent, a temperature of $100 \mathrm{C}$, and irradiation in sealed microwave vials over a period of three hours.

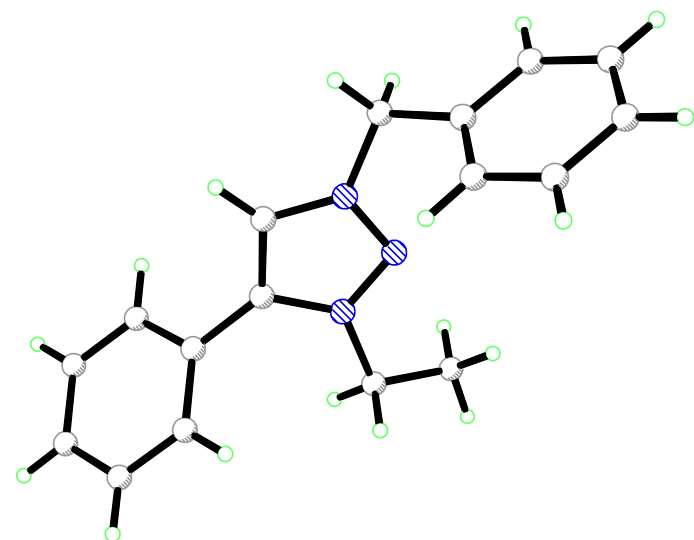

Figure 1: X-ray structure of 1-benzyl-3-ethyl-4-phenyl-1,2,3triazolium iodide $\mathbf{3}$ (cation shown)

The reactivity of the substituted triazolium cations was first investigated under various reductive conditions. We initially examined the Birch reduction of 1-benzyl-3-methyl-4-phenyl1,2,3-triazolium iodide 4 in the hope of reducing the level of unsaturation of the cationic aromatic five-membered ring, thus obtaining products that would be susceptible to hydrolysis, but without success. The alternative of hydride reduction was examined next, and because of the expected low reactivity of the aromatic cationic $\pi$-system as a hydride acceptor, we choose the highly reactive lithium aluminium hydride as the reducing agent. The triazolium salt was indeed slowly reduced to form a neutral product, but we were surprised to find that this proved to be a debenzylated 1,5-disubstituted 1,2,3-triazole (24\% yield), rather than a reduced dihydro-1,2,3-triazole (Scheme 2). The unexpected formation of the 1,5-regioisomer, however, is itself an important result, since it opens the way for an inexpensive copper-mediated 'click' reaction to access the 1,5disubstituted products, which normally require ruthenium catalysis. ${ }^{16}$ 
A recent report has pointed out the strategic advantages of the availability of both the 1,3- and 1,5- disubstituted 1,2,3-triazole regioisomers. ${ }^{25}$ In that work, Koguchi and Izawa developed a specialized azide (3,4-dimethoxybenzyl azide) cycloaddition partner for the CuAAC step. After installing a selection of alkyl groups at N3, the 3,4-dimethoxybenzyl protecting group was removed using either ammonium nitrate (presumably acting as a mild acid) to promote an $S_{\mathrm{N}} 1$ process suited to the powerful stabilization of the benzylic cation by the dimethoxy substitution of the arene) or through an oxidative procedure using ceric ammonium nitrate (the electron-rich arene is easily oxidized).

We reasoned that our alkylative debenzylation of $\mathbf{2}$ could provide a more general and more easily executed solution to the 1,3- to 1,5- disubstitution interconversion problem. We were encouraged by the fact that, although the $\mathrm{LiAlH}_{4}$ reaction was low yielding, the main problem seemed to be lack of reactivity (the starting material was recovered in 66\% yield). In search of a more effective debenzylation reaction, we switched from hydride donors to other nucleophile types (NaOMe in methanol and NaOEt in ethanol) but in this case it was the methyl group, not the benzyl group, that was removed, reforming 1 in $96 \%$ yield.

The $\mathrm{LiAlH}_{4}$ reagent thus appeared to have a special role in the debenzylation reaction. We reasoned that the reagent might be acting as a base, rather than as a nucleophile inducing direct displacement of the triazole; in place of the nucleophilic bases methoxide and ethoxide, we therefore chose the stronger nonnucleophilic base potassium tert-butoxide. When this was employed, we were immediately rewarded with excellent results in the debenzylation step (Scheme 2). The expected 1,5disubstited 1,2,3-trazoles 6-9 were isolated in 49-93\% yields.

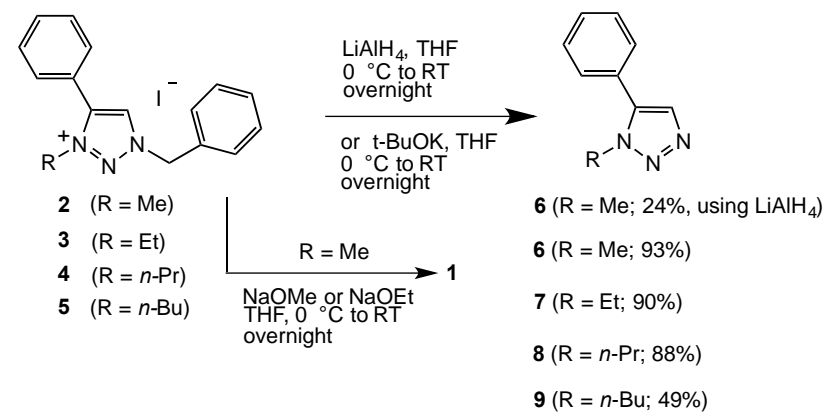

Scheme 2. Debenzylation reactions of 1-benzyl-3-alkyltriazolium salts

We conjectured that the base induces deprotonation at the iminium nitrogen substituent, to produce a nitrogen ylid. The iodide counter-ion, freed from any ion pairing, can then cause debenzylation by nucleophilic attack at the benzylic carbon atom. Additional support for this mechanism was obtained upon application of the 1,3- to 1,5- disubstitution conversion methodology to mono-triazole $\mathbf{1 0}$, which we had previously synthesized. ${ }^{26}$ We were successful in changing the regiochemistry of the triazole, but the methyl ester group was also lost (Scheme 3). Analysis of the $N$-alkylation step showed a mixture of two products, which after being exposed to the tertbutoxide-mediated debenzylation reaction, gave a single product, identified as 1-(2-cyano-pent-4-ynyl)-substituted 1,5 triazole 11. These results can be accounted for if the mixture of products observed following the methylation step consisted of the expected malononitrile $\mathbf{1 2}$ and the decarboxylated nitrile 13.

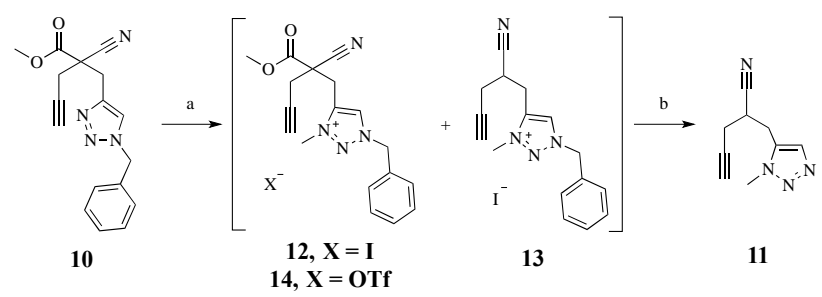

Scheme 3. Conversion of the 1,4-disubstituted triazole $\mathbf{1 0}$ into the 1,5-disubstituted triazole 11; a: MeI or MeOTf (5 equiv.) $\mathrm{MeCN}$, microwave; b: t-BuOK, THF, $0{ }^{\circ} \mathrm{C}$ to RT.

We reasoned that the decarboxylation may result from Krapcho decarboxylation in the presence of the nucleophilic iodide counterion. ${ }^{27}$ In order to avoid the presence of iodide in both the methylation and debenzylation steps, the microwave-mediated methylation of $\mathbf{1 0}$ was repeated using methyl triflate, which produced only the trisubstituted 1,2,3-triazolium triflate salt 14 in $96 \%$ yield. Attempted debenzylation of $\mathbf{1 4}$ by treatment with potassium tert-butoxide then, however, proved unsuccessful, only starting material being recovered, supporting the contention that iodide also plays an important role in the debenzylation process.

Attempted debenzylation of the simpler triazolium iodide salt $\mathbf{2}$ was therefore carried out with the potassium tert-butoxide omitted from the reaction. No reaction was observed, suggesting that both iodide and potassium tert-butoxide are indeed required for successful debenzylation.

In summary, we have developed an efficient generally applicable microwave-mediated method to convert 1-benzyl-4phenyl-1,2,3-triazoles, available through inexpensive coppercatalysed 'click' cycloaddition reactions, into 1-alkyl-5-phenyl 1,2,3-triazoles, ${ }^{28}$ without the need to re-engineer the chiralligand-controlled cyclization for the rather different organoruthenium catalysts, normally required for selective preparation of 1,5-disubstituted 1,2,3-triazoles by 'click' chemistry. The process is especially effective for methyl and ethyl alkyl groups. While ruthenium-catalysed synthesis of 1,5disubstituted 1,2,3-triazoles remains an important process, the results described here provide a low cost alternative by a simple, high-yielding selective alkylative debenzylation process.

\section{Acknowledgment}

This investigation has enjoyed the support of EU Interreg IVA (project 4061). We are indebted to the EPSRC UK National Mass Spectrometry Facility at the University of Wales, Swansea.

\section{Supporting Information}

YES (this text will be updated with links prior to publication) 


\section{Primary Data}

NO (this text will be deleted prior to publication)

\section{References and Notes}

(1) Tornøe, C. W.; Meldal, M. In Peptides 2001, Proc. Am. Pept. Symp.; American Peptide Society and Kluwer Academic Publishers: San Diego, 2001; pp. 263-264.

(2) Rostovtsev, V. V; Green, L. G.; Fokin, V. V; Sharpless, K. B. Angew Chem. Int. Ed. 2002, 41, 2596-2599.

(3) Tornøe, C. W.; Christensen, C.; Meldal, M. J. Org. Chem 2002, 67, 3057-3064.

(4) Such, G. K.; Johnston, A. P. R.; Liang, K.; Caruso, F. Progress in Polymer Science 2012, 37, 985-1003; Binder, W. H.; Sachsenhofer, R. Macromol. Rapid Commun. 2007, 28, 15-54.

(5) See for example Bock, V. D.; Hiemstra, H.; Van Maarseveen, J. H. Eur. J. Org. Chem. 2006, 2006, 51-68; Yang, J.; Ye, T.; Ma, D.; Zhang, Q. Synthetic Metals 2011, 161, 330-334; Johansson, H.; Pedersen, D. S. Eur. J. Org. Chem. 2012, 2012, 4267-4281.

(6) Crowley, J. D.; McMorran, D. A. Topics in Heterocyclic Chemistry, 2012, 28, 31

(7) Chuprakov, S.; Kwok, S. W.; Zhang, L.; Lercher, L.; Fokin, V. V. J. Am Chem. Soc. 2009, 131, 18034-18035.

(8) Agalave, S. G., Maujan, S. R.; Pore, V. S. Chem. Asian J. 2011, 6 , 2696-2718.

(9) Lima-Neto, R. G.; Cavalcante, N. N. M.; Srivastava, R. M.; Mendonça Junior, F. J. B.; Wanderley, A. G.; Neves, R. P.; Dos Anjos, J. V Molecules 2012, 17, 5882-92.

(10) Millward, S. W.; Agnew, H. D.; Lai, B.; Lee, S. S.; Lim, J.; Nag, A.; Pitram, S.; Rohde, R.; Heath, J. R. Integr. Biol. 2013, 5, 87-95.

(11) Tullis, J. S.; VanRens, J. C.; Natchus, M. G.; Clark, M. P.; De, B.; Hsieh, L. C.; Janusz, M. J. Bioorg. Med. Chem. Lett. 2003, 13, 1665-1668.

(12) Monceaux, C. J.; Hirata-Fukae, C.; Lam, P. C.-H.; Totrov, M. M.; Matsuoka, Y.; Carlier, P. R. Bioorg. Med. Chem. Lett. 2011, 21 3992-3996.

(13) Khan, S. S.; Hanelt, S.; Liebscher, J. Arkivoc 2009, 193-208.

(14) (a) Miura, T,; Yamauchi, M.; Murakami, M. Chem. Commun. 2009, 1470. (b) Chattopadhyay, B.; Gevorgyan, V. Org. Lett. 2011, 13, 3746-3749.

(15) Horneff, T.; Chuprakov, S.; Chernyak, N.; Gevorgyan, V.; Fokin, V. V. J. Am. Chem. Soc. 2008, 130, 14972-14974. DOI: 10.1021/ja805079v; Chuprakov, S.; Kwok, S. W.; Fokin, V. V. J Am Chem Soc. 2013, 135, 4652-4655.

(16) Zhang, L.; Chen, X.; Xue, P.; Sun, H. H. Y.; Williams, I. D.; Sharpless, K. B.; Fokin, V. V; Jia, G. J. Am. Chem. Soc. 2005, 127, 15998-15999; Johansson, J.; Lincoln, P.; Nordén, B.; Kann, N. J. Org. Chem. 2011, 76, 2355-2359.

(17) The 1,5 regioisomer can also be accessed from alkynyl Grignard reagents: (a) Krasiński, A.; Fokin, V. V.; Sharpless, K. B. Org. Lett. 2004, 6, 1237-1240; under base-catalysed conditions: (b) Kwok, S. K.; Fotsing, J. R.; Fraser, R. J.; Rodionov, V. O.; Fokin, V. V. Org. Lett. 2010, 12, 4217-4219; and using sulfonyl azides: (c) MezaAviña, M. E.; Patel, M. K.; Lee, C. B.; Dietz, T. J.; Croatt, M. P. Org. Lett. 2011, 13, 2984-2987. Rare earth metal catalysis: (d) Hong, L.; Lin, W.; Zhang, F.; Liua, R.; Zhou, X. Chem. Commun. 2013, 49, 5589-5591. Palladium catalysis: (e) Chuprakov, S.; Chernyak, N. Dudnik, A.; Gevorgyan, V. Org. Lett. 2007, 9, 2333-2336; Metalfree: (f) Kloss, F.; Köhn, U.; Jahn, B. O.; Hager, M. D.; Görls, H.; Schubert, U. S. Chem. Asian J. 2011, 6, 2816-24; (g) Lima, C. G. S.; Ali, A.; van Berkel, S. S.; Westermann, B.; Paixão, M. W. Chem. Commun. 2015, 51, 10784-10796 (review). From azide- $\beta$ ketophosphonate cycloaddition: (h) González-Calderón, D.; Fuentes-Benítes, A.; Díaz-Torres, E.; González-González, C. A.; González-Romero, C. Eur. J. Org. Chem. 2016, 668-672. From Azide-vinyl bromide cycloaddition: (i) Wu, L.; Chen, Y.; Luo, J.; Sun, Q.; Peng, M.; Lin, O. Tetrahedron Lett. 2014, 55, 3847-3850.
(18) Readily available by the microwave-assisted CuAAC reaction in 93\% yield: Appukkuttan, P; Dehaen, W.; Fokin, V. V.; Van der Eycken, E. Org. Lett. 2004, 6, 4223.

(19) Kacprzak, K. Synlett 2005, 943-946.

(20) Hanelt, S.; Liebscher, J. Synlett 2008, 2008, 1058-1060.

(21) $\mathrm{N}$-Alkylation of 1,4-substituted 1,2,3-triazoles with alkyl halides always occurs on N-3: Gompper, R. Chem. Ber. 1957, 90, 374-382.

(22) Mathew, P.; Neels, A.; Albrecht, N. J. Am. Chem. Soc. 2008, 130, 13534-13535.

(23) $\mathrm{C}_{17} \mathrm{H}_{18} \mathrm{IN}_{3}, \mathrm{M}=391.25$, monoclinic, space group $\mathrm{P} 21 / \mathrm{c}$, a = 17.436(4), b = 7.723(2), c = 12.207(3) $\AA, V=1628.2(6) \AA^{3}, Z=4$, $\mu(\mathrm{MoKa})=0.71075,9847$ independent reflections, (Rint $=$ 0.0594), $\mathrm{R} 1[\mathrm{I}>2 \mathrm{~s}(\mathrm{I})=0.0376$, $\mathrm{wR} 2$ (all reflections) $=0.0874$. Xray data has been deposited at at the Cambridge Crystallographic Data Centre, assigned to deposition number CCDC 1479260.

(24) For 1, the triazole proton is at $7.66 \mathrm{ppm}$ in the ${ }^{1} \mathrm{H}$ NMR spectrum, and moves to $9.33 \mathrm{ppm}$ in the triazolium salt 2 . Similar chemical shift changes have been previously observed in related structures; see for example Saravanakumar, R.; Ramkumar, V.; Sankararaman, S. Organometallics 2011, 30, 1689.

(25) Koguchi, S.; Izawa, K. Synthesis, 2012, 44, 3603-3608.

(26) Stephenson, G. R.; Buttress, J. P.; Deschamps, D.; Lancelot, M.; Martin, J. P.; Sheldon, A. I. G.; Alayrac, C.; Gaumont A. C.; Page, P. C. B. Synlett 2013, 2723-2729.

(27) Krapcho, A. P.; Ciganek, E. in Organic Reactions, John Wiley \& Sons, Inc., Hoboken, New Jersey, USA, 2013, pp. 1-536.

(28) General procedure for the formation of the triazolium salts from 1-benzyl-4-phenyl 1,2,3-triazoles

1-benzyl-4-phenyl 1,2,3-triazole was dissolved in MeCN in a microwave vial, and the alkyl halide ( $5 \mathrm{eq}$ ) added. The reaction was irradiated in the microwave instrument for $3 \mathrm{~h}$ at $100{ }^{\circ} \mathrm{C}$. Solvents were removed under reduced pressure to yield the triazolium salt.

1-Benzyl-3-methyl-4-phenyl-1H-1,2,3-triazolium iodide 2

Prepared according to the general procedure from 1 (1.66 g, 7.07 $\mathrm{mmol})$ and iodomethane (1.73 $\mathrm{mL}, 4.98 \mathrm{~g}, 35.10 \mathrm{mmol})$. Compound 2 was isolated as a pale yellow solid ( $2.79 \mathrm{~g}, 93 \%), \mathrm{mp}$ 133-135 ${ }^{\circ} \mathrm{C}$; IR (neat): 3467, 3040, 1611, 1493, 1455, 1155, 768, 746, $699 \mathrm{~cm}^{-1} ;{ }^{1} \mathrm{H} \mathrm{NMR}\left(\mathrm{CDCl}_{3}, 400 \mathrm{MHz}\right): \delta 9.33(\mathrm{~s}, 1 \mathrm{H}), 7.69-7.60$ (m, 4H), 7.54-7.40 (m, 3H), 7.37-7.33 (m, 3H), 5.97 (s, 2H), $4.26(\mathrm{~s}$, $3 \mathrm{H}) ;{ }^{13} \mathrm{C}$ NMR $\left(\mathrm{CDCl}_{3}, 126 \mathrm{MHz}\right) \delta 143.2,132.2,131.4,130.1,130.1$, $129.8,129.7,129.6,129.4,121.7,57.6,39.6$.

General procedure for the debenzylation of triazolium salts using tBuOK

1-Benzyl-3-alkyl-4-phenyl triazolium iodide was dissolved in THF, and the solution cooled to $0{ }^{\circ} \mathrm{C}$. $t$-BuOK (2.5 eq) was added and the reaction stirred overnight. $\mathrm{H}_{2} \mathrm{O}$ was added, and the mixture stirred for 30 minutes and filtered through Celite. The solution was extracted using EtOAc, the solvents removed under reduced pressure to give the desired 1,5-disubstituted triazole.

\section{1-Methyl-5-phenyl-1H-1,2,3-triazole 6}

Prepared according to the general procedure from 2 (0.78 g, 2.05 $\mathrm{mmol}$ ) and ${ }^{\mathrm{BuOK}}(0.61 \mathrm{~g}, 5.46 \mathrm{mmol})$ dissolved in THF (45 mL). The crude product was purified by column chromatography, eluting with 1:1 EtOAC/petroleum ether, yielding the titled compound 6 as an orange oil ( $0.31 \mathrm{~g}, 93 \%)$; IR (neat): 3060, 3030, 2953, 1732, 1484, 1454, 1245, $767 \mathrm{~cm}^{-1} ;{ }^{1} \mathrm{H}$ NMR $\left(\mathrm{CDCl}_{3}, 500\right.$ MHz): $\delta 7.73(\mathrm{~s}, 1 \mathrm{H}), 7.57-7.45(\mathrm{~m}, 3 \mathrm{H}), 7.45-7.35(\mathrm{~m}, 2 \mathrm{H}), 4.08(\mathrm{~s}$, $3 \mathrm{H}) ;{ }^{13} \mathrm{C} \mathrm{NMR}\left(\mathrm{CDCl}_{3}, 126 \mathrm{MHz}\right) \delta 129.3,128.7,127.1,35.7,14.3$ (quaternary signals not observed). 